\title{
Fertility-Limiting Behavior and Contraceptive Choice Among Men in Nepal
}

\author{
By Govinda P. \\ Dahal, SabuS. \\ Padmadas and \\ P.R. Andrew Hinde
}

Govinda P. Dahal is director, Centre for Nepal Studies UK, Southampton, UK. Sabu S. Padmadas and P.R. Andrew Hinde are senior lecturers in demography and social statistics, both at the Southampton Statistical Sciences Research Institute and the Centre for Global Health, Population,

Poverty and Policy, University of Southampton, Southampton, UK. CONTEXT: Contraceptive choices among men who want no more children have been little explored in South Asia,
particularly in Nepal, where fertility rates have remained high over the last few decades.

METHODS: Using the 2001 Nepal Demographic and Health Survey couple data set, multinomial logistic regression analyses were conducted for 1,041 married men aged 20 or older who had at least one living child and wanted no more children. Regression models examined relationships between selected characteristics and men's reported contraceptive use, and predicted probabilities were estimated to assess interactions between ecological zone, family composition and method choice. The primary goal was to determine whether the number and sex of living children influenced contraceptive use.

RESULTS: Twenty-four percent of men who wanted no more children were not using any contraceptive method at the time of the survey, $30 \%$ reported that their wives were sterilized, $12 \%$ had had a vasectomy, $7 \%$ were using condoms and $27 \%$ used other temporary methods. The probability of relying on permanent methods was highest among men who had at least two living sons and lowest among those who had only daughters, while the probability of using no method was highest among those who had only daughters.

CONCLUSION: In Nepal, men who report a desire to have no more children are likely to choose permanent methods only after they have two living sons.

International Family Planning Perspectives, 2008, 34(1):6-14

It is widely acknowledged that men in developing countries make most of the decisions regarding family formation. ${ }^{1-4}$ Despite women's increasing influence on household decision making, their preferences regarding contraceptive choices and family size may not translate into practice unless they conform to their husbands' wishes. ${ }^{5,6}$ Studies conducted in Africa and Latin America have shown that more than a quarter of men who want to limit or postpone their wives' childbearing do not use any method to prevent unwanted pregnancy. ${ }^{7}$ Men's decision to use a method depends on a range of factors, ${ }^{7-10}$ particularly the extent to which couples negotiate family planning matters and reach compromises with each other. ${ }^{11-15}$

Male involvement in family planning should be viewed in terms of not only the share of male method use, but also men's attitudes regarding method choices and family size preferences. ${ }^{16}$ A better understanding of male involvement requires a systematic analysis of men's attitudes toward spacing and limiting behavior. ${ }^{17,18}$ This study examined contraceptive use among Nepalese men who wanted to limit their family size and the underlying factors that influence their choice of a particular method.

This analysis focused on why men choose different methods and on the level of unmet need for contraception among men who want to limit family size. If these men are able to act effectively on their preferences and are certain about their intentions, most of them would probably be using permanent methods. If they use a method that is not effective or if they do not use any method, their wives may be at risk of experiencing an unwanted birth or an abortion. Interesting empirical questions are: What proportion of these men are using permanent methods? Does this proportion vary according to the men's characteristics? If they use a permanent method, is it likely to be a male or a female method? And, for men who say they want no more children but who are not using permanent methods, do they lack access to such methods, do their wives object, do they themselves have objections to rendering themselves infertile or do they think they might change their minds later about wanting no more children? Unfortunately, the last question cannot be answered in this study because the 2001 Nepal Demographic and Health Survey (DHS), from which our data came, did not ask users about their reasons for choosing a particular method; instead, it probed for reasons only among men who were not using any method at the time of survey.

\section{BACKGROUND}

Men were long considered to be beyond the scope of family planning programs; the reasons included the notions that reproduction is primarily a women's issue and that men usually do not take responsibility for reproductive health and family planning. ${ }^{16,19,20}$ Furthermore, there are few malebased contraceptives, as most of the available methods are 
female-based. In the 1990s, however, there was a shift toward promoting informed contraceptive choices and a client-centered approach that called for men to take an increased role in and responsibility for reproductive health and family planning. ${ }^{16}$

Despite these efforts, there has been little increase in the use of methods that require male participation, especially in settings where the levels of both fertility and HIV infection are high. ${ }^{7,9,21-23}$ According to the United Nations, in 2005 only $3 \%$ of married women in developing regions were relying on male sterilization and another 3\% were using condoms. ${ }^{24}$ (In India, the method most often used by women who want to limit family size is female sterilization, whereas in Bangladesh very few limiters rely on permanent methods.) Indeed, only 14\% of married women in these regions were relying on methods that required active male participation-vasectomy, condoms, periodic abstinence or withdrawal. This low use of malebased methods has been attributed to lack of awareness of different methods, opposition from husbands, lack of method satisfaction, fear of side effects and poor access to family planning services. ${ }^{25-29}$

In South Asia, contraceptive prevalence is generally low (48\% in 2000, including traditional methods), ${ }^{24}$ particularly in Nepal, where the total fertility rate is high compared with that of other Asian countries. ${ }^{30}$ Nepal's contraceptive prevalence rose from 3\% in 1976 to 39\% in 2001 ; its total fertility rate decreased from 6.3 births per woman to 4.1 births over the same period. In 1997, the Nepalese government adopted a 20-year goal to achieve a national family norm of two children. Furthermore, in its ninth development plan (1997-2002), the government stated its commitment to promoting greater male responsibility for reproductive health and family planning, with the objective of achieving replacement-level fertility by $2017 .^{30}$

In 2001, the percentage of married couples who used any modern method was 35\%, and the share of modern male-based methods was only $26 \%$ of overall modern method use, with three-fourths of modern method users relying on female-based methods. ${ }^{30}$ One of the factors that has led to low use of contraceptive methods in Nepal is son preference. $^{31-35}$ Studies conducted by Leone et al. ${ }^{31}$ (based on female responses from the 1996 Nepal DHS) and Stash $^{33}$ (based on district-level couple data) have shown that son preference is prevalent across sociocultural and ethnic groups. Stash's study represents a methodologically strong approach to understanding family size preferences among couples in Nepal, yet her findings have not been validated using national-level data. The present study attempted to bridge this gap by analyzing national data on contraceptive choices among men who have stated a desire to limit their family size. An important focus of this study was to examine the effect of the number and sex composition of living children on men's contraceptive behavior, and to explore the social and demographic factors that mediate these effects.

\section{DATA AND METHODS}

Usually, data on family planning and family formation are derived from women's responses to survey questionnaires. Since 1990, the DHS has been collecting nationally representative data from men on a range of reproductive health issues, including contraceptive use and fertility behavior. However, these data have received little attention compared with data collected from women, possibly because men are thought to give less reliable information, especially regarding their attitudes and behaviors related to family planning.

The 2001 DHS was the first Nepal survey to collect data from a nationally representative sample of men. The male data set includes 2,261 ever-married males aged 15-59, and the female data set includes 8,726 ever-married females aged 15-49. The matched couple data set $(\mathrm{N}=1,858)$ comprises currently married individuals from both of these samples, and so some data that are missing for husbands can be ascertained from their wives' responses. In the couple data set, the average age at first marriage was 19.9 years (standard deviation, 3.9 years) for men and 16.5 years (standard deviation, 2.8 years) for women.

Of these married men, we excluded 188 who did not have any living children at the time of the survey, 18 who were younger than 20 (of whom only two wanted no more children), 431 who wanted to have more children, 89 whose wives were pregnant, 71 whose wives had experienced menopause or hysterectomy and 20 whose wives were infecund or subfecund. (We excluded men whose wives were pregnant or unable to bear more children because it was difficult to determine whether these men's responses regarding their own fertility intentions accounted for the current status of their wives.) Thus, our sample included 1,041 men aged 20 or older who had at least one living child and said that they wanted no more children.*

The dependent variable in our analysis was contraceptive use as reported by Nepalese men, coded into five categories: female sterilization, male sterilization, condoms, other temporary method and nonuse. The other temporary method category consisted of the injectable, periodic abstinence and withdrawal, which constituted about three-quarters of this category, and the pill and the IUD, which made up the remainder. Men's responses regarding contraceptive use were considered reliable because they usually decide which method to use. However, it is possible that wives use methods such as the injectable without the knowledge of their husbands because of fear of opposition from them or other family members. In the couple data set, $98 \%$ of permanent method use was reported consistently by both husbands and wives, whereas there were substantial inconsistencies in reporting the use of tempo-

* Of these men, 31 reported that they currently had more than one wife. However, the DHS did not ask women about polyandrous unions. Details regarding family planning were available only for married women whose husbands were also interviewed, and not for polyandrous or polygamous unions. 
rary methods. Inconsistency was most notable for condom use: Thirty-two percent of men who reported using condoms were married to women who did not report such use, which indicates possible condom use by men outside their current marital relationship. Because we wanted to better understand men's fertility intentions, we were primarily interested in their responses; a comparison of responses between husbands and wives was beyond the scope of this analysis.

Our main interest was to assess whether the number and sex composition of living children influenced men's reports of their intention to limit family size. However, the male data set provided no information on the number of living sons and daughters in families, so we relied on the responses of men's wives, and assumed that the reported sons and daughters were born within the current marital relationship. The DHS asked women about the number of sons and daughters who lived at home or elsewhere at the time of survey. We did not expect a linear or even monotonic relationship between number of sons or number of children and contraceptive use-because men who live in remote areas lack access to contraceptive methods-and so classified these variables as categorical and not continuous. Moreover, because previous research had suggested that although Nepalese couples prefer sons to daughters, many want at least one daughter, ${ }^{33,34}$ we considered a range of family size and sex composition categories to obtain a detailed picture of the possible impact of these factors on contraceptive use. We constructed a composite variable that combined family size and the number of sons and daughters in the family. After carefully scrutinizing the data and taking into account current preferences for family size and sex composition of children in Nepal, we classified this variable into 13 categories.

In constructing this variable, we accounted for the fact that only 16 men who reported wanting no more children had just one living child (10 had a son and six had a daughter). The combination of two sons and one daughter is perceived as particularly desirable by couples in Nepal. ${ }^{33,34}$ Despite a government policy that encourages couples to have only two children, regardless of sex, ${ }^{36}$ the average desired family size in the 2001 DHS is 2.6 children and the average desired number of sons is about two. Finally, we considered men with only sons or only daughters as separate categories, since their contraceptive behavior may be different from that of men who have both sons and daughters. We hypothesized that even though men reported wanting no more children, they would be less likely to use a permanent method until they had achieved their desired number of two sons and one daughter.

Other variables were men's age, place and ecological zone of residence, education, occupation, ethnicity, whether husbands communicated with spouses about family planning (frequently, occasionally, never) and shared in decision making about spouses' health care (with other family members or with spouse), and men's exposure to family planning messages in the mass media (radio, TV or newspapers) in the last few months preceding the survey.

\section{Analysis}

Chi-square tests were conducted to determine significant differences in the bivariate analyses. All variables were screened for multicollinearity before being included in the multinomial logistic regression models, which assessed associations between family composition and other characteristics and use of specific contraceptive methods. For the regression models, we merged four additional categories of the family composition variable into the "other" category used in the bivariate analyses, since exploratory analysis showed no significant differences among them (hence the "other" reference category comprised families with three sons and one daughter, with five or six children of both sexes, and with seven or more children). We estimated multinomial beta coefficients for a reduced model (controlling only for respondents' age and urban or rural residence) to determine the independent effect of family composition on method choice, and for a full model to assess the effects of all variables.

To test for a possible interaction between ecological zone and family composition, we also calculated the predicted probabilities that men would use each contraceptive method. To obtain an accurate comparison, we included only men whose characteristics matched the reference categories of the various social and demographic variables: They were aged 36-59, lived in rural areas and had no education, worked in agriculture, were not upper caste Hill Hindus, never communicated with their spouses about family planning, made decisions about their spouses' health care alone and had no recent exposure to family planning messages in the mass media. Hence this subsample represented poor, uneducated, rural men with a traditional outlook on life.

\section{RESULTS}

\section{Sample Characteristics}

Among surveyed Nepalese men who had at least one living child, more than seven in 10 wanted no more children. Some $55 \%$ of men who did not want more children were aged 20-39 (Table 1); 84\% were from rural areas and 57\% were from the Terai (plains) ecological zone. Thirty-seven percent of men had no education, whereas 34\% had a secondary or higher level of education. Most were engaged in agricultural activities (63\%), and only 8\% were employed in the professional sector. The largest ethnic groups were upper caste Hill Hindus (34\%), Janjatis (28\%) and Dalits (22\%). Dalit men were poorer than those in other ethnic groups (not shown).

Forty-one percent of men who wanted no more children said they never communicated with their spouses about family planning, and 25\% said they frequently did so. A large majority ( $82 \%$ ) reported that they alone made decisions about their wives' health care. A third of the men had had no exposure to family planning messages in the 
mass media in the last few months, while about four in 10 had been exposed to messages through either radio, TV or newspapers. The most common family composition among those who did not want more children was two sons and one daughter (15\%); only 3\% had no living sons. Generally, men who wanted more children tended to have rather small families, or had more daughters than sons.

\section{Contraceptive Use}

Among the 1,041 men who wanted no more children, 24\% reported not using any contraceptive method at the time of the survey, while 30\% reported that their wives had been sterilized, 12\% had been sterilized themselves, $7 \%$ used condoms and $27 \%$ used another temporary method (Table 2, page 10). Among the 787 contraceptive users, $45 \%$ relied on temporary methods: the injectable (21\%), condoms (9\%), the pill (4\%), the implant (1\%), the IUD ( $1 \%$ ) and traditional methods (9\%-not shown). Modern male methods constituted $25 \%$ of the method mix ( $9 \%$ condoms and $16 \%$ male sterilization), whereas female sterilization made up $40 \%$ of the mix.

Contraceptive use varied by age-group: Men aged 20-29 reported the lowest levels of female and male sterilization ( $21 \%$ and 9\%, respectively) and the highest level of condom use (11\%), and, along with those aged 30-39, were the most likely to use other temporary methods (31-32\%). Men aged 40-59 were the most likely to rely on female and male sterilization (34\% and 13\%, respectively).* Among men in the youngest and oldest age-groups, $27-28 \%$ used no contraceptives.

Men with two sons and one daughter were more likely to be using permanent methods than men with other family combinations (62\%, three-quarters of whom were relying on female sterilization). Otherwise, sterilization was most common among men who had four children, at least two of whom were sons, and among those with three or more children, all of whom were sons (47-57\%). In contrast, among the few men who had only daughters, one in five reported using permanent methods. These results indicate that Nepalese men generally desire more than one son and are unlikely to resort to sterilization when they have no sons, even though they express a desire to have no more children. Condom use was highest among men who had three or fewer children (excluding those with two sons and a daughter) or had no living sons (10-13\%). In general, men with five or more children were most likely to not use contraceptives (32-39\%).

Contraceptive use also varied by residence: A higher proportion of men who lived in rural than in urban areas used no contraceptives ( $26 \%$ vs. $15 \%$ ), and a lower proportion used temporary methods other than the condom ( $26 \%$ vs. $36 \%$ ). Men living in the mountain zone were more likely than those in the Terai to use male sterilization ( $24 \%$ vs. $8 \%$ ) or no contraceptives ( $40 \%$ vs. $18 \%$ ), where-

*Male sterilization was aggressively promoted by the Nepalese government during the 1970 s, and it later became an acceptable method among young people, especially in the 1990s (sources: references 39 and 40).
TABLE 1. Percentage distribution of currently married men aged 20 or older who had at least one living child, by selected characteristics, according to fertility intention, Nepal, 2001

\begin{tabular}{lll} 
Characteristic & $\begin{array}{l}\text { Did not want } \\
\text { more children } \\
(\mathrm{N}=1,041)\end{array}$ & $\begin{array}{l}\text { Wanted more } \\
\text { children } \\
(\mathrm{N}=431)\end{array}$ \\
\hline Age*** & & \\
$20-29$ & 14.4 & 57.1 \\
$30-39$ & 41.0 & 31.1 \\
$40-59$ & 44.6 & 11.8
\end{tabular}

No. and sex of living children***

One or two: sons only

Two: 1 son, 1 daughter

Three: 1 son, 2 daughters

Three: 2 sons, 1 daughter

Four: 1 son, 3 daughters

Four: 2 sons, 2 daughters

Four: 3 sons, 1 daughter

Five: 2 sons, 3 daughters

Five: $\geq 3$ sons, at least 1 daughter $\quad 5.3$

Six: $\geq 2$ sons, at least 1 daughter $\quad 6.2$

Three or more: sons only $\quad 5.8$

Daughters only 2.9

Other†

10.0

Residence $^{* *}$

Urban

15.9

Rural

Ecological zone ${ }^{* * *}$

Mountain

Hill

Terai

56.5

27.4

12.3

5.8

1.6
3.9

3.9
1.4

1.4
0.5

0.9

0.0

1.2

0.2

18.6

26.2

Education

zsecondary $\quad 34.2$

Primary

28.9

None

36.9

Occupation**

Professional

Clerical/sales/services

Manual skilled/unskilled

Agriculture

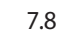

14.6

14.3

63.3

16.2

36.9

46.9

Ethnicity***

Janjati

Dalit

Terai Hindu

Newar

27.7

21.6

10.6

6.5

Upper caste Hill Hindu

33.6

33.9

33.4

32.7

Husband communicates with spouse about family planning***

Frequently

Occasionally

24.6

34.4

Never

41.0

16.2

34.6

49.2

Husband decides about spouse's

health care ${ }^{* * *}$

With other family members $\quad 3.7 \quad 11.1$

$\begin{array}{lll}\text { With spouse } & 14.5 & 13.7\end{array}$

Alone

81.8

75.2

Exposure to family planning messages

in last few months**

Radio, TV and newspaper

Any two media

One medium

None

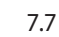

14.4

43.3

34.6

3.5

13.9
18.6

64.0

27.4

32.1
9.6

2.6

28.3

Total

100.0

4.4

10.0

42.0

43.6

100.0

${ }^{* *} \mathrm{p}<.01 .{ }^{* * *} \mathrm{p}<.001$. Includes families with one son and four daughters, one son and five daughters, or seven or more children. Note: $p$-values are based on chi-square tests. 
TABLE 2. Percentage distribution of married men who did not want more children, by current contraceptive method, according to selected characteristics

\begin{tabular}{lllllll} 
Characteristic & $\begin{array}{l}\text { Female } \\
\text { sterili- } \\
\text { zation } \\
(\mathrm{N}=312)\end{array}$ & $\begin{array}{l}\text { Male } \\
\text { sterili- } \\
\text { zation } \\
(\mathrm{N}=122)\end{array}$ & $\begin{array}{l}\text { Condom } \\
(\mathrm{N}=68)\end{array}$ & $\begin{array}{l}\text { Other } \\
\text { temporary } \\
\text { method } \\
(\mathrm{N}=285)\end{array}$ & $\begin{array}{l}\mathrm{None}(\mathrm{N}=254) \\
\text { Total } \\
(\mathrm{N}=1,041)\end{array}$ \\
\hline All & $\mathbf{3 0 . 0}$ & $\mathbf{1 1 . 7}$ & $\mathbf{6 . 5}$ & $\mathbf{2 7 . 4}$ & $\mathbf{2 4 . 4}$ & $\mathbf{1 0 0 . 0}$
\end{tabular}

Age****

$20-29$

$30-39$

40-59

21.3

28.6

34.6

No. and sex of living children***

One or two: sons only 28.9

Two: 1 son, 1 daughter $\quad 17.5$

Three: 1 son, 2 daughters 24.7

Three: 2 sons, 1 daughter $\quad 47.8$

Four: 1 son, 3 daughters 26.1

Four: 2 sons, 2 daughters $\quad 42.2$

Four: 3 sons, 1 daughter $\quad 30.6$

Five: 2 sons, 3 daughters $\quad 25.0$

Five: $\geq 3$ sons, at least

1 daughter
Six: $\geq 2$ sons, at least

1 daughter

Three or more:sons only $\quad 43.3$

Daughters only $\quad 16.7$

Other†

8.7
11.0
13.4

10.7
8.0

\section{3}

$32.3 \quad 20.1 \quad 100.0$

\section{0}

100.0

11.1

13.6

9.0

13.8

15.2

14.7

16.1

11.8

12.7

12.3

11.7

3.3

3.8
Residence**

Urban

Rural

30.7

29.8

Ecological zone***

Mountain

Hill

Terai

2.5
13.9
44.7

Education***

$\geq$ secondary

Primary

None

29.5
28.6
31.5

Occupation***

Professional

Clerical/sales/services

Manual skilled/unskilled

Agriculture

Ethnicity***

Janjati

Dalit

Terai Hindu

Newar

Upper caste Hill Hindu

9.6

12.1

8.4
6.2

6.2

6.2

36.1

25.7

15.1

26.2

100.0

100.0

24.0
14.2
7.8

\section{3}

30.6

33.1

23.5

39.7

29.8

18.2

100.0

14.0
11.6
9.6

\section{5}

\section{3}

28.6

23.7

14.6

100.0

$25.9 \quad 100.0$

$32.3 \quad 100.0$

Husband communicates with spouse

about family planning ${ }^{* * *}$

Frequently

Occasionally

25.0
22.6

39.1

19.8
11.8
5.4
12.1

18.5

\section{7}

32.2

13.6

13.6
16.4

100.0

5.4

5.3

25.2

21.5

28.2

100.0

100.0

$\begin{array}{rrrrr}13.9 & 6.9 & 30.9 & 22.9 & 100.0 \\ 5.3 & 4.9 & 20.4 & 35.6 & 100.0 \\ 0.0 & 1.8 & 20.9 & 23.6 & 100.0 \\ 8.8 & 5.9 & 35.3 & 20.6 & 100.0 \\ 18.3 & 8.9 & 29.4 & 19.4 & 100.0\end{array}$

Never

9.4
8.9
15.5

11.3
7.5
2.8

as they were much less likely to rely on female sterilization (3\% vs. 45\%).

Men at all levels of education reported similar rates of female and male sterilization (29-32\% and 10-14\%, respectively), whereas those with at least a secondary education reported the highest levels of condom or other temporary method use (12\% and 30\%, respectively) and the lowest level of contraceptive nonuse (15\%). Method choice also differed by occupation: Men working in the professional sector reported the lowest rate of female sterilization (24\%) and the highest rates of male sterilization and condom use (20\% and 19\%, respectively), while men who had manual or agricultural jobs were the most likely to use no contraceptives (22\% and 28\%). Furthermore, there were ethnic differences in men's reliance on sterilization: The Terai Hindus relied on female sterilization (54\%) and reported no use of male sterilization, whereas upper caste Hill Hindus were the most likely to have been sterilized themselves (18\%). Among all ethnic groups, the Newars were the most likely to use temporary methods other than the condom (35\%), and the Dalits were the most likely to report nonuse (36\%).

Husbands who never communicated with their spouses about family planning reported the greatest reliance on female and male sterilization (39\% and 16\%, respectively), and the lowest levels of condom and other temporary method use ( $3 \%$ and $12 \%$, respectively); these men also had the highest rate of contraceptive nonuse (30\%). In addition, husbands who made decisions about their spouses' health care without consulting others were the most likely to rely on female sterilization (32\%). When family members other than wives were involved in these decisions, men reported the highest rate of contraceptive nonuse (47\%), even though a high proportion still relied on female sterilization (29\%). Finally, men who had been exposed to family planning messages through all three mass media were the most likely to use condoms or other temporary methods ( $14 \%$ and $39 \%$, respectively), whereas those who had been exposed to no media messages were the most likely to use no contraceptives (32\%).

\section{Multinomial Analysis}

In analyses of the association between family composition and use of specific methods (vs. no use) that controlled only for age and urban or rural residence, relationships between family composition categories and method use were evident. Each method was associated with 4-5 family composition categories. Men who had 2-4 living children, with at least two sons, or an only child who was a son, were significantly more likely to rely on either female or male sterilization (vs. not using any method) than were men in the reference category (not shown). Compared with men in the reference category, those who had two sons and two daughters and those with small families made up of only one or two sons were more likely to use condoms than to use no method. In comparison with older men, those aged 20-35 were less likely to adopt sterilization than to use no 
method, and those residing in urban areas were more likely than those in rural areas to use either condoms or other temporary methods rather than no method.

When the remaining background variables were added in a second set of multinomial analyses, about half of the significant associations between family composition and contraceptive use in the first model lost significance (e.g., the likelihood that men whose only children were two sons would use male sterilization rather than no method), and the magnitude of most of the other associations decreased (Table 3). Nonetheless, the results confirmed those of the previous analyses that son preference had a strong influence on contraceptive choice, even among men who expressed a desire to have no more children. Specifically, compared with men in the reference category, those who had three or four children, two of whom were sons, were significantly more likely to rely on male or female sterilization than to use no method, while those with only sons, regardless of family size, were more likely to rely on female sterilization; men with two sons and two daughters were also more likely to use condoms than to use no contraceptive. Perhaps the simplest general statement that can be made on the basis of these results is that, even though Nepalese men may want no more children, they are unlikely to resort to permanent birth control unless they already have two living sons.

The likelihood of using a male-based modern method instead of no method was higher among men with at least a secondary education than among those with no schooling. Men's occupation had no association with method choice, except for condom use among professionals. Upper caste Hill Hindus were significantly more likely than other ethnic groups to use male sterilization (vs. no method), and those living in the mountain or hill zones were less likely than those in the Terai to rely on female sterilization instead of using no method.

Compared with men who never discussed family planning with their wives, those who frequently or occasionally discussed it were more likely to use condoms or other temporary method than to use no method. Furthermore, reliance on sterilization or on temporary methods other than condoms (vs. no use) was less likely among men who consulted with other family members about health care for their spouses than among men who decided alone. Finally, compared with men who had no recent exposure to family planning messages in the mass media, those with such exposure from at least one medium (radio, TV or newspapers) were more likely to use temporary methods other than condoms rather than no method.

The analysis of a possible interaction between ecological zone and family composition was limited to a subsample of poor, uneducated, rural men who never communicated with their spouses about family planning and who had no recent exposure to family planning messages in the mass media (Table 4, page 12). As such, they represented a group of men who were unlikely to use temporary methods and likely to rely on sterilization. Therefore, these
TABLE 3. Beta coefficients (and standard errors) from multinomial logistic regression analyses assessing associations between selected characteristics and use of specific methods, full model

Characteristic

$\begin{array}{lll}\text { Female } & \text { Male } & \text { Condom } \\ \text { sterilization } & \text { sterilization } & \text { vs.no use } \\ \text { vs.no use } & \text { vs.no use } & \end{array}$

Other

temporary

method

vs. no use

\section{Age}

20-35

36-59 (ref)

$-0.70(0.22)^{* *}-0.42(0.27)$

$0.41(0.33) \quad-0.12(0.21)$

$\begin{array}{llll}0.00 & 0.00 & 0.00 & 0.00\end{array}$

\section{No. and sex of living children}

Two: 1 son, 1 daughter

Three: 1 son, 2 daughters

Three: 2 sons, 1 daughter

Four: 1 son, 3 daughters

Four: 2 sons, 2 daughters

Three or more: sons only

Daughters only

Othert (ref)

$\begin{array}{llll}1.46(0.42)^{* * *} & 0.89(0.51) & 1.02(0.57) & 0.82(0.41)^{*} \\ 0.49(0.40) & 0.42(0.44) & 0.41(0.54) & 0.13(0.35) \\ 0.59(0.39) & 0.32(0.49) & 0.94(0.54) & 0.59(0.36) \\ 1.40(0.30)^{* * *} & 0.84(0.36)^{* *} & -0.03(0.55) & -0.27(0.33) \\ 0.64(0.50) & 0.48(0.56) & -0.75(1.11) & 0.27(0.46) \\ 1.98(0.41)^{* * *} & 1.63(0.46)^{* * *} & 1.78(0.56)^{* *} & 1.00(0.42)^{*} \\ 1.33(0.43)^{* *} & 0.47(0.54) & 0.31(0.76) & 0.12(0.46) \\ -0.55(0.62) & -1.35(1.11) & 0.05(0.76) & -0.50(0.52)\end{array}$

Residence

Urban

Rural (ref)

$-0.28(0.31)$

0.00

0.00

Ecological zone

Mountain

0.00

$0.05(0.44)$

$0.43(0.31)$

0.00

Hill

Terai (ref)

$-3.99(0.63)^{* * *}$

$-1.96(0.24)^{* * *}-0.31(0.29)$

$-1.12(0.61)$

$-0.61(0.30)^{*}$

Terai(ref)

Education

$\geq$ secondary

Primary

None (ref)

$0.69(0.28)^{* *}$

$0.73(0.34)^{*}$

$-0.25(0.34)$

$-0.53(0.22)^{*}$

0.00

\section{Occupation}

Professional

Clerical/sales/services

Manual skilled/unskilled

Agriculture (ref)

0.00

$0.38(0.30) \quad 0.42(0.44)$

$0.21(0.28)$

$0.08(0.23)$

0.00

Ethnicity

Upper caste Hill Hindu

Other (ref)

$0.07(0.46)$

$0.71(0.49)$

0.00

Husband communicates with spouse

about family planning

Frequently

Occasionally

$0.50(0.32)$

$0.32(0.39)$

$1.02(0.52)^{*}$

$-0.04(0.16)$

$0.53(0.29)$

$-0.29(0.44)$

$0.06(0.48)$

$0.21(0.32)$

0.00

0.00

0.00

0.00

Never (ref)

$-0.41(0.27)$

$-0.35(0.23)$

$-0.30(0.33)$
$-0.48(0.28)$
0.00

$1.26(0.42)^{* *} \quad 1.46(0.27)^{* * *}$

$0.93(0.40)^{*} \quad 1.43(0.23)^{* * *}$

$0.00 \quad 0.00$

\section{Husband decides about spouse's}

health care

With other family members

With spouse

$1.19(0.46)^{* *}$

$-1.53(0.78)^{*}$

$-0.92(0.70)-1.93(0.59)^{* *}$

Alone (ref)

$-0.25(0.30)$

$0.11(0.32)$

$-0.38(0.48)$

0.00

0.00

\begin{tabular}{l}
$\begin{array}{l}\text { Exposure to family planning messages } \\
\text { in last few months }\end{array}$ \\
$\begin{array}{lllll}\text { Radio, TV and newspaper } & 0.58(0.53) & 0.76(0.62) & 0.86(0.64) & 1.30(0.51)^{*} \\
\text { Any two media } & 0.61(0.33) & 0.98(0.41)^{* *} & 0.26(0.50) & 0.72(0.34)^{* *} \\
\text { One medium } & 0.59(0.23)^{* *} & 0.50(0.28) & 0.09(0.37) & 0.71(0.22)^{* * *} \\
\text { None (ref) } & 0.00 & 0.00 & 0.00 & 0.00 \\
& & & & \\
\text { Intercept } & 0.04(0.22) & -1.71(0.31)^{* * *} & -3.33(0.48)^{* * *} & -1.47(0.26)^{* * *} \\
-2 \text { log-likelihood 2352.9 } & & & & \end{array}$ \\
\hline
\end{tabular}

${ }^{*} \mathrm{p}<$.05. ${ }^{* *} \mathrm{p}<.01 .{ }^{* * *} \mathrm{p}<.001$. Includes families with three sons and one daughter, with five or six children of both sexes, and with seven or more children. Note: $r$ f=reference.

probabilities should be interpreted as indicating the relative influence of ecological zone and family composition on contraceptive use rather than overall percentages of men using particular methods. In general, contraceptive 


\begin{tabular}{|c|c|c|c|c|c|c|}
\hline $\begin{array}{l}\text { Zone and family } \\
\text { composition }\end{array}$ & $\begin{array}{l}\text { Female } \\
\text { sterili- } \\
\text { zation }\end{array}$ & $\begin{array}{l}\text { Male } \\
\text { sterili- } \\
\text { zation }\end{array}$ & Condom & $\begin{array}{l}\text { Other } \\
\text { temporary } \\
\text { method }\end{array}$ & None & Total \\
\hline \multicolumn{7}{|l|}{ Mountain } \\
\hline One or two: sons only & 4.5 & 24.2 & 1.8 & 15.3 & 54.2 & 100.0 \\
\hline Two: 1 son, 1 daughter & 2.1 & 19.0 & 1.2 & 9.6 & 68.1 & 100.0 \\
\hline Three: 1 son, 2 daughters & 2.2 & 16.4 & 2.0 & 14.6 & 64.8 & 100.0 \\
\hline Three: 2 sons, 1 daughter & 4.8 & 26.4 & 0.7 & 5.9 & 62.1 & 100.0 \\
\hline Four: 1 son, 3 daughters & 2.4 & 19.7 & 0.4 & 10.9 & 66.7 & 100.0 \\
\hline Four: 2 sons, 2 daughters & 5.6 & 37.7 & 2.8 & 13.6 & 40.2 & 100.0 \\
\hline Three or more: sons only & 4.8 & 19.3 & 1.0 & 9.2 & 65.7 & 100.0 \\
\hline Daughters only & 1.0 & 4.2 & 1.0 & 6.6 & 87.3 & 100.0 \\
\hline Othert & 1.4 & 13.7 & 0.9 & 9.3 & 74.7 & 100.0 \\
\hline \multicolumn{7}{|l|}{ Hill } \\
\hline One or two: sons only & 27.1 & 13.8 & 3.3 & 13.1 & 42.7 & 100.0 \\
\hline Two: 1 son, 1 daughter & 14.6 & 12.3 & 2.6 & 9.4 & 61.2 & 100.0 \\
\hline Three: 1 son, 2 daughters & 15.0 & 10.3 & 4.1 & 13.9 & 56.7 & 100.0 \\
\hline Three: 2 sons, 1 daughter & 29.2 & 15.1 & 1.3 & 5.1 & 49.3 & 100.0 \\
\hline Four: 1 son, 3 daughters & 16.5 & 12.6 & 0.8 & 10.5 & 59.5 & 100.0 \\
\hline Four: 2 sons, 2 daughters & 32.6 & 20.6 & 5.0 & 11.2 & 30.5 & 100.0 \\
\hline Three or more: sons only & 28.4 & 10.8 & 1.9 & 7.8 & 51.1 & 100.0 \\
\hline Daughters only & 6.9 & 2.8 & 2.2 & 6.7 & 81.5 & 100.0 \\
\hline Othert & 10.2 & 9.1 & 1.9 & 9.4 & 69.4 & 100.0 \\
\hline \multicolumn{7}{|l|}{ Terai } \\
\hline One or two: sons only & 68.6 & 6.7 & 1.5 & 8.0 & 15.2 & 100.0 \\
\hline Two: 1 son, 1 daughter & 51.7 & 8.3 & 1.6 & 7.9 & 30.4 & 100.0 \\
\hline Three: 1 son, 2 daughters & 51.7 & 6.8 & 2.5 & 11.4 & 27.5 & 100.0 \\
\hline Three: 2 sons, 1 daughter & 72.2 & 7.2 & 0.6 & 3.0 & 17.1 & 100.0 \\
\hline Four: 1 son, 3 daughters & 55.0 & 8.1 & 0.5 & 8.4 & 27.9 & 100.0 \\
\hline Four: 2 sons, 2 daughters & 73.4 & 8.9 & 2.0 & 6.0 & 9.7 & 100.0 \\
\hline Three or more: sons only & 71.2 & 5.2 & 0.9 & 4.7 & 18.0 & 100.0 \\
\hline Daughters only & 33.1 & 2.6 & 1.9 & 7.7 & 54.9 & 100.0 \\
\hline Othert & 41.9 & 7.2 & 1.4 & 9.2 & 40.2 & 100.0 \\
\hline
\end{tabular}

tIncludes families with three sons and one daughter, with five or six children of both sexes, and with seven or more children. Notes: Includes men whose characteristics matched the reference categories of the social and demographic variables in Table 3:They were aged 36-59, lived in rural areas and had no education, worked in agriculture, were not upper caste Hill Hindus, never communicated with their spouses about family planning, made decisions about their spouses' health care alone and had no recent exposure to family planning messages in the mass media. Percentages may not total 100.0 because of rounding.

use was highest in the Terai zone and lowest in the mountain zone. Within each zone, probabilities of nonuse were consistently highest among men who had only daughters. The men who were most likely to be using contraceptives in all three zones were those with two sons and two daughters, followed by those whose families consisted of one or two sons, and then those with two sons and one daughter.

In the Terai zone, female sterilization was the dominant method. With increasing altitude, male sterilization became more common and its association with family composition became more pronounced, so that in the mountain zone it was relied on mostly by men with two sons. The inverse pattern was found for female sterilization: The probability of relying on that method was dramatically lower among men residing in the mountain region than among those in the Terai.

\section{DISCUSSION}

Among Nepalese men aged 20 or older who had at least one living child, more than seven in 10 wanted no more children, and a quarter of these men were not using any form of contraception. Many contraceptive users rely on temporary methods, yet the failure rate among such users who want to limit their fertility is unknown. And although the use of modern male methods is higher in Nepal than in neighboring countries (e.g., India and Bangladesh), ${ }^{24}$ these methods account for only a fourth of the contraceptive method mix among men who want no more children. Because of the high levels of both unwanted fertility and men's desire to limit family size, it is critical to promote a range of contraceptive options and wider availability of client-oriented services. The use of modern male methods should be particularly encouraged, as they are as safe as female methods and less expensive. ${ }^{21,22,37-39}$

While it is known that couples' preference for sons influences fertility levels in Nepal, ${ }^{31-35}$ this study found clear evidence that contraceptive use among men who wanted no more children varied substantially by the number and sex composition of their family. Our findings confirm that son preference is an influential factor in both the high level of nonuse and the method mix among men who claim they want no more children. Nepalese men prefer sons over daughters for cultural reasons: Traditionally, sons light their parents' funeral pyres and perform the ceremony on the anniversary of their death. ${ }^{40}$ They are also responsible for supporting parents in old age because the state pension system for elderly people is both insecure and minimal. ${ }^{32,34,40}$

Although the use of permanent methods would be expected to be low among young men, this may not always be the case if they marry early and attain their desired family size (including sons) at a relatively young age. We found that contraceptive nonuse was least likely among men aged 30-39, even though condom use was highest among younger men.

Male sterilization was more common in the hill and mountain zones than in the Terai, whereas female sterilization was most prevalent in the Terai. Men living in remote hill and mountain zones who desire to limit their family size have limited access to any methods other than sterilization. ${ }^{41}$ The Terai has more accessible services than the hill zone, which in turn has more accessible services and more resources than the mountain zone. ${ }^{42}$ Men in the Terai tend to avoid male methods, especially sterilization, for cultural and religious reasons. For example, because vasectomy is perceived as equivalent to castration, sterilized men from this region are generally deemed to be "polluted" and therefore barred from performing certain religious rituals. ${ }^{40}$ The higher use of female temporary methods among couples in urban areas indicates greater service accessibility and availability of method choices.

The higher use of female sterilization compared with vasectomy suggests that service provision in Nepal may focus more on women than men, though cultural factors may also be involved. It is surprising that among men belonging to the Terai Hindu ethnic group who relied on a permanent method, none had been sterilized. Dahal ${ }^{40}$ found that a large proportion of women whose husbands were manual workers favored female sterilization because 
of their fear that vasectomies would render men weak and too ill to work, and hence potentially impair their ability to support the family.

The main contribution of this study is its use of data collected from men on contraceptive use and fertility intentions, which have been largely unexplored in the Nepalese context. However, one limitation of the study is the lack of qualitative information on the contraceptive choices that men make to limit family size. For example, why do nearly half of men who want to limit their fertility rely on temporary methods rather than permanent methods? Our analysis clearly showed that having at least two sons in the family strongly influenced men to accept permanent methods. Yet because of sample size limitations, we could not explore all possible combinations of the number and sex of children. Furthermore, men who had no sons might have understated their true desire to limit family size, partially because of widely publicized governmental policies that promote smaller family size. Another limitation is that our results are based on cross-sectional data collected at a single time point, and longitudinal data would improve our understanding of the dynamics of men's fertility attitudes and contraceptive behavior.

Our findings suggest a number of policy implications that need to be addressed by the reproductive health programs operating in Nepal. Existing programs are not reaching all men-especially those who live in remote mountainous areas, those in socially excluded groups (e.g., the Dalit) and those who lack education. Nepalese men who want no more children but who are not currently using a contraceptive likely have a high level of unmet need for modern methods. Program efforts should also focus on strategies to enhance men's awareness of contraceptives by providing them with information on the advantages and disadvantages of a wide range of methods, and by underscoring the importance of improved communication and shared decision making within the family.

\section{REFERENCES}

1. Bankole A and Singh S, Couples' fertility and contraceptive decisionmaking in developing countries: hearing the man's voice, International Family Planning Perspectives, 1998, 24(1):15-24.

2. De Silva P, Male influence on female contraception, in: Senanayake $\mathrm{P}$ and Kleinman RL, eds., Family Planning-Meeting Challenges: Promoting Choices, Carnforth, UK: Parthenon Publishing Group, 1993, pp. 579-582.

3. Piotrow PT et al., Changing men's attitudes and behavior: the Zimbabwe male motivation project, Studies in Family Planning, 1992, 23(6):365-375.

4. Freedman R and Sun T, Comparison of the reporting of the use of contraception by husbands and wives, as related to their desire for additional children, Taiwan Population Studies Working Paper, Ann Arbor, MI, USA: University of Michigan Population Studies Center, 1974, No. 28

5. Morgan SP and Niraula B, Gender inequality and fertility in two Nepali villages, Population and Development Review, 1995 21(3):541-561.

6. Dodoo F N-A, Men matter: additive and interactive gendered preferences and reproductive behavior in Kenya, Demography, 1998, 35(2):229-242.

7. The Alan Guttmacher Institute (AGI), In Their Own Right: Addressing the Sexual and Reproductive Health Needs of Men, New York: AGI, 2003.

8. Feyisetan B and Casterline JB, Fertility preferences and contraceptive change in developing countries, International Family Planning Perspectives, 2000, 26(3):100-109.

9. Ezeh AC, Seroussi M and Raggers H, Men's Fertility, Contraceptive Use, and Reproductive Preferences, Calverton, MD, USA: Macro International, Inc., 1996

10. Roudi F and Ashford L, Men and Family Planning in Africa, Washington, DC: Population Reference Bureau, 1996.

11. Mullany BC, Hindin MJ and Becker S, Can women's autonomy impede male involvement in pregnancy health in Katmandu, Nepal? Social Science \& Medicine, 2005, 61(9):1993-2006.

12. Kamal N, Inter-spousal communication on family planning as a determinant of the use of modern contraception in Bangladesh, Journal of Family Welfare, 1999, 45(1):31-43.

13. Sharan M and Valente TW, Spousal communication and family planning adoption: effects of a radio drama serial in Nepal, International Family Planning Perspectives, 2002, 28(1):16-25.

14. Miller K, Zulu EM and Watkins SC, Husband-wife survey responses in Malawi, Studies in Family Planning, 2001, 32(2):161-174

15. Raju S, Husband-wife communication and contraceptive behavior, Journal of Family Welfare, 1987, 33(4):44-48.

16. International Conference on Population and Development, Programme of Action, New York: United Nations (UN), 1994.

17. Drennan M, Reproductive health: new perspectives on men's participation, Population Reports, 1998, Series J, No. 46.

18. Masson OK and Herbert LS, Husbands' versus wives' fertility goals and use of contraception: the influence of gender context in five Asian countries, Demography, 2000, 37(3):299-311.

19. Necchi S, Men, Family Formation and Reproduction, Policy and Research Paper, Paris: International Union for the Scientific Study of Population, 1999, No. 17.

20. Raju S and Leonard A, eds., Men as Supportive Partners in Reproductive Health: Moving from Rhetoric to Reality, New Delhi: Population Council, 2000.

21. Salem R, Men's surveys: new findings, Population Reports, 2004, Series M, No. 18

22. U.S. Agency for International Development Interagency Gender Working Group, Reaching Men to Improve Reproductive Health for All: Resource Guide, Washington, DC: Population Reference Bureau, 2003.

23. Hulton L and Falkingham J, Male contraceptive knowledge and practice: what do we know? Reproductive Health Matters, 1996, 4(7):90-100.

24. UN, World contraceptive use 2005 wall chart, New York: Department of Economic and Social Affairs, Population Division, UN, 2005.

25. Casterline JB, Zaba AS and Manhaj MH, Obstacles to contraceptive use in Pakistan: a study in Punjab, Studies in Family Planning, 2001, 32(2):95-110

26. Casterline JB and Sinding SW, Unmet need for family planning in developing countries and implications for population policy, Population and Development Review, 2000, 26(4):691-723.

27. Bongaarts J and Bruce J, The causes of unmet need for contraception and the social content of services, Studies in Family Planning, 1995, 26(2):57-75.

28. Bankole A, Desired fertility and fertility behaviour among the Yoruba of Nigeria: a study of couples' preferences and subsequent fertility, Population Studies, 1995, 49(2):317-328.

29. Shrestha A, Stoeckel J and Tuladhar JM, The KAP gap in Nepal: reasons for non-use of contraception among couples with unmet need for family planning, Asia-Pacific Population Journal, 1991, 6(1):25-38.

30. Nepal Ministry of Health, New ERA and ORC Macro, Nepal Demographic and Health Survey, 2001, Calverton, MD, USA: Nepal Ministry of Health, New ERA and ORC Macro, 2002. 
31. Leone T, Matthews Z and Zuanna GD, Impact and determinants of sex preference in Nepal, International Family Planning Perspectives, 2003, 29(2):69-75.

32. Stash S, Explanations of unmet need for contraception in Chitwan, Nepal, Studies in Family Planning, 1999, 30(4):267-287.

33. Stash S, Ideal-family-size and sex composition preferences among wives and husbands in Nepal, Studies in Family Planning, 1996 27(2):107-118

34. Karki YB, Sex preference and the value of sons and daughters in Nepal, Studies in Family Planning, 1988, 19(3):169-178.

35. Schuler SR and Goldstein MC, Family planning in Nepal from the user's and non-user's perspectives, Studies in Family Planning, 1986, 17(2): 66-77.

36. Nepal National Planning Commission, Tenth Plan (2002-2007), Singh Durbar, Nepal: Department of Printing, 2002

37. Ringheim K, Factors that determine prevalence of use of contraceptive methods for men, Studies in Family Planning, 1993, 24(2):87-99.

38. Mbizvo MT and Adamchak DJ, Male fertility regulation-a study on acceptance among men in Zimbabwe, Central African Journal of Medicine, 1992, 38(2):52-57.

39. Tuladhar JM, Supply Aspects of Meeting Demand for Family Planning New York: United Nations Population Fund, 1989.

40. Dahal GP, Men's sexual and reproductive behavior in Nepal, unpublished dissertation, Southampton, UK: Division of Social Statistics, University of Southampton, 2005.

41. Nepal Ministry of Health, Annual Report 2002/2003, Kathmandu Nepal: Department of Health Services, 2003

42. Thapa S and Friedman M, Female sterilization in Nepal: a comparison of two types of service delivery, International Family Planning Perspectives, 1998, 24(2):78-83.

\section{RESUMEN}

Contexto: Las decisiones sobre el uso de anticonceptivos de los hombres que no desean más hijos han sido poco exploradas en Asia del Sur, especialmente en Nepal, en donde las tasas de fecundidad han permanecido altas durante las últimas décadas. Métodos: Utilizando el conjunto de datos pareados de la Encuesta de Demografía y Salud de Nepal de 2001, se llevó a cabo análisis de regresión logística multinomial para 1,041 hombres casados de 20 años o mayores que tenían al menos un hijo vivo y que no deseaban tener más hijos. Los modelos de regresión examinaron las relaciones entre las características selectas y el uso de anticonceptivos reportado por los hombres. Además, se hizo una estimación de las probabilidades pronosticadas para evaluar las interacciones entre la zona ecológica en que vivía el entrevistado, su composición familiar y el método elegido. El objetivo principal era determinar si el número y sexo de los hijos vivos influenciaba el uso de anticonceptivos.

Resultados: Veinticuatro por ciento de los hombres que no deseaban más hijos no estaba usando método anticonceptivo alguno en el momento de la encuesta, el 30\% reportó que sus es- posas estaban esterilizadas, el 12\% había tenido una vasectomía, el $7 \%$ estaba usando condones y el $27 \%$ usaba otros métodos temporales. La probabilidad de recurrir a métodos permanentes fue la más alta en hombres que tenían al menos dos hijos varones vivos y fue la más baja en aquellos que tenían solamente hijas.

Conclusión: En Nepal, los hombres que reportan su deseo de no tener más hijos, tienen probabilidad de elegir métodos permanentes solamente después de que tienen dos hijos varones vivos.

\section{RÉSUMÉS}

Contexte: Les choix contraceptifs des hommes qui ne désirent plus avoir d'enfants n'ont guère été examinés en Asie du Sud, et plus particulièrement au Népal, où les indices de fécondité demeurent élevés depuis plusieurs décennies.

Méthodes: Sur la base des données de couple de l'Enquête démographique et de santé népalaise de 2001, des analyses de régression logistique multinomiale ont été effectuées pour 1.041 hommes mariés, âgés de 20 ans ou plus et qui avaient au moins un enfant en vie mais n'en désiraient plus. Les modèles de régression ont examiné le rapport entre certaines caractéristiques et la pratique contraceptive déclarée des hommes. Les probabilités prédites ont été estimées pour évaluer l'interaction entre la zone écologique, la composition de la famille et le choix de méthode. Le but principal était de déterminer l'influence éventuelle du nombre et du sexe des enfants en vie sur la pratique contraceptive.

Résultats: Vingt-quatre pour cent des hommes qui ne désiraient plus avoir d'enfants ne pratiquaient aucune méthode contraceptive au moment de l'enquête; $30 \%$ ont déclaré que leur épouse s'était fait stériliser; $12 \%$ avaient subi une vasectomie; $7 \%$ avaient recours au préservatif et $27 \%$ à d'autres méthodes temporaires. Le recours aux méthodes permanentes s'est révélé le plus probable chez les hommes qui avaient au moins deux fils en vie et le moins probable parmi ceux qui n'avaient que des filles. L'absence de méthode était la plus probable aussi parmi les hommes qui n'avaient que des filles.

Conclusion: Au Népal, les hommes qui déclarent ne plus désirer d'enfants sont susceptibles de ne choisir de méthodes permanentes qu'une fois pères de deux fils en vie.

\section{Acknowledgments}

We thank MEASURE DHS, Macro International, Inc., Calverton, MD, USA, for providing us with the DHS data and the UK Overseas Research Student Awards Scheme for financial assistance for the first author.

Author contact:ssp@soton.ac.uk 